\title{
GC-MS Analysis, Antimicrobial and Antioxidant Activity of Sudanes Adansoina digitata L; (Malvaceae) Fixed Oil
}

\author{
Mohammed Bahreldin Hussein ${ }^{1}$, Mosab Nouraldein Mohammed Hamad ${ }^{2 *}$
}

${ }^{1}$ Department of Chemistry, Faculty of Science, University of Kordofan, Elobeid, Sudan

${ }^{2}$ Phylum of Medical Parasitology, Medical Laboratory Sciences Department, Faculty of Health Science, Elsheikh Abdallah Elbadri University, Berber, Sudan

\author{
DOI: $10.36348 /$ sjmps.2020.v06i08.004 $\quad$ | Received: 10.08 .2020 | Accepted: 20.08 .2020 | Published: 22.08 .2020 \\ *Corresponding author: Mosab Nouraldein Mohammed Hamad
}

\section{Abstract}

Medicinal plants are source of a great economic value. Plants herbs are naturally gifted at the synthesis of medicinal compounds. The extraction and characterization of bioactive compounds from medicinal plants have resulted in the discovery of new drugs with high therapeutic value. Baobab Adansonia digitata L., (Malvaceae) seeds were collected from El-Obeid, North Kordofan state Sudan, and were extracted with hexane as solvent the extracted oil was analyzed by GC-MS. Twenty four constituents were detected the major constituents are: 9-octadecanoic acid methyl ester (25.08), 9,12-Octadecadienoic acid (Z,Z)-, methyl ester (23.08), Hexadecanoic acid, methyl ester (22.78), Methyl stearate (6.86) and Methyl 2-octylcyclopropene-1-heptanoate (6.08). In the well diffusion bioassay the oil showed significant activity against Bacillus subtilis, Pseudomonas aeroginosa, Staphylococcus aureus, and the yeast Candida albicans but it was partially active against Escherichia coli. The antioxidant activity of the extracted oil was evaluated using the standard 2 , 2diphenyl-1-picrylhydrazyl (DPPH) $0.5 \mathrm{ml}$. The antioxidant activity of the extracted oil was $19.00 \pm 0.08$.

Keywords: Baobab, fixed oil, GC-MS, antimicrobial and antioxidant activity.

Copyright @ 2020: This is an open-access article distributed under the terms of the Creative Commons Attribution license which permits unrestricted use, distribution, and reproduction in any medium for non-commercial use (NonCommercial, or CC-BY-NC) provided the original author and source are credited.

\section{INTRODUCTION}

Medicine, in several developing countries, using local traditions and beliefs, is still the mainstay of health care. As defined by WHO, health is a state of complete physical, mental, and social wellbeing and not merely the absence of disease or infirmity. The practise of traditional medicine is widespread in China, India, Japan, Pakistan, Sri Lanka and Thailand. In China about $40 \%$ of the total medicinal consumption is attributed to traditional tribal medicines [1].

Adansonia digitata L; Malvaceae commonly known as Baobab indigenous to Africa where it is found in many countries such as Zimbabwe, Malawi, Mozambique, Mali, South Africa, Benin, Sudan, Senegal, the Ivory Coast, Kenya, Cameroon, Tanzania and Uganda [2]. The various parts of the plant (seeds, fruits, leaves, barks, stems and roots) have traditionally been used to treat various diseases include malaria, fever, tuberculosis, microbial infections, anaemia, diarrhoea, toothache and dysentery in many African countries [3, 4]. Baobab has numerous biological properties including antimicrobial, Analgesic, antipyretic, antiviral, anti-oxidant, Anti-insecticidal and anti-inflammatory activities [5-8]. From different plant parts various nutritional and phytochemical ingredients were separated such as vitamin- $\mathrm{C}$, minerals, amino acid, flavonoids, steroids, epicatechin, fatty acids, campesterol and tocopherol [2, 9]. This study was conducted to investigate the chemical constituents and biological activity of Adansonia digitata seeds oil.

\section{Material and Methods Plant material}

Seeds of Adansonia digitata was collected in December (2018) from El-Obeid North Kordofan state Sudan. The plant was authenticated by a plant taxonomist at the Department of Botany Faculty of Science University of Kordofan Sudan. All chemicals used in this experiment were of analytical grade purchased from Sigma Chemical Co. (USA).

\section{Instruments \\ GC-MS analysis was conducted on a Shimadzo GC-MSQP2010 Ultra instrument with a RTX-5MS column (30m, length; $0.25 \mathrm{~mm}$ diameter; $0.25 \mu \mathrm{m}$, thickness). And anti-oxidant activity was measured on spectrophotometer.}




\section{Test organisms}

The Adansonia digitata seeds oil was screened for antimicrobial activity using the standard microorganisms as shown in (Table No.1).

\section{Methods}

\section{Extraction of oil}

Dry powdered seeds of Adansonia digitata (50.0g) were placed in thimble of soxhlet apparatus. A dry pre-weighed solvent flask containing hexane and condenser were attached and oil was extracted for 7 hours. The thimble was removed and hexane was retained. The excess of hexane was then evaporated on a hot water bath and the flask was dried in a desiccator and weighed. Oil percentage was calculated by subtracting the weight of empty flask from the weight of the flask containing the oil after solvent evaporation dividing it by the weight of the sample taken in grams.

\section{GC-MS analysis}

The qualitative and quantitative analysis of the sample was carried out by using GC-MS technique model (GCMS-QP2010-Ultra) from japans Shimadzu Company, with serial number 020525101565SA and capillary column (Rtx-5ms-30m $\times 0.25 \mathrm{~mm} \times 0.25 \mu \mathrm{m})$. The sample was injected by using split mode, helium as the carrier gas passed with flow rate $1.61 \mathrm{ml} / \mathrm{min}$, the temperature program was started from $60^{\circ} \mathrm{C}$ with rate $10^{\circ} \mathrm{C} / \mathrm{min}$ to $300^{\circ} \mathrm{C}$ as final temperature degree with 3 minutes hold time, the injection port temperature was $300^{\circ} \mathrm{C}$, the ion source temperature was $200^{\circ} \mathrm{C}$ and the interface temperature was $250^{\circ} \mathrm{C}$. The sample was analyzed by using scan mode in the range of $\mathrm{m} / \mathrm{z} 40$ 500 charges to ratio and the total run time was 27 minutes. Identification of components for the sample was achieved by comparing their retention index and mass fragmentation patents with those available in the library of National Institute of Standards and Technology (NIST) [10].

\section{In vitro antimicrobial assay \\ Preparation of bacterial suspensions}

One $\mathrm{ml}$ aliquots of a 24 hours broth culture of the test organisms were aseptically distributed on to nutrient agar slopes and incubated at $37^{\circ} \mathrm{C}$ for 24 hours. The bacterial growth was harvested and washed off with $100 \mathrm{ml}$ sterile normal saline, to produce a suspension containing about 108-109 colony forming unit per $\mathrm{ml}$. The suspension was stored in the refrigerator at $4^{\circ} \mathrm{C}$ till used. The average number of viable organisms per $\mathrm{ml}$ of the stock suspension was determined by means of the surface viable counting technique. Serial dilutions of the stock suspension were made in sterile normal saline solution and $0.02 \mathrm{ml}$ volumes of the appropriate dilution were transferred by micro pipette onto the surface of dried nutrient agar plates. The plates were allowed to stand for two hours at room temperature for the drops to dry and then incubated at $37^{\circ} \mathrm{C}$ for 24 hours. After incubation, the number of developed colonies in each drop was counted. The average number of colonies per drop $(0.02$ $\mathrm{ml}$ ) was multiplied by 50 and by the dilution factor to give the viable count of the stock suspension, expressed as the number of colony forming units per $\mathrm{ml}$ suspension. Each time a fresh stock suspension was prepared. All the above experimental conditions were maintained constant so that suspensions with very close viable counts would be obtained [11].

\section{Preparation of fungal suspension}

The fungal cultures were maintained on Sabouraud dextrose agar, incubated at $25^{\circ} \mathrm{C}$ for 4 days. The fungal growth was harvested and washed with sterile normal saline and finally suspension in $100 \mathrm{ml}$ of sterile normal saline, and the suspension were stored in the refrigerator until used [11].

\section{Testing of antibacterial susceptibility}

Disc diffusion method was used to screen the antibacterial activity of plant extracts and performed by using Mueller Hinton Agar (MHA). The experiment was carried out according to the National Committee for Clinical Laboratory Standards Guidelines Bacterial suspension was diluted with sterile 5 minutes. Sterilized filter paper discs (Whitman No.1, $6 \mathrm{~mm}$ in diameter) were placed on the surface of the MHA and soaked with $20 \mu \mathrm{l}$ of a solution of each plant extracts. The inoculated plates were incubated at $37^{\circ} \mathrm{C}$ for $24 \mathrm{~h}$ in the inverted position. The diameters $(\mathrm{mm})$ of the inhibition zones were measured [11].

\section{Antioxidant assay}

The DPPH radical scavenging was determined according to the method of Shimada et al.. with some modification. In 96-wells plate, the test samples were allowed to react with $2.2 \mathrm{Di}$ (4-tert-octylphenyl)-1picryl-hydrazyl stable free radical (DPPH) for half an hour at $37^{\circ} \mathrm{C}$. The concentration of DPPH was kept as $(300 \mu \mathrm{M})$. The test samples were dissolved in DMSO while DPPH was prepared in ethanol. After incubation, decrease in absorbance was measured at $517 \mathrm{~nm}$ using multiplayer reader spectrophotometer. Percentage radical scavenging activity by samples was determined in comparison with a DMSO treated control group. All tests and analysis were run in triplicate [12].

\section{RESULTS AND DISCUSSION GC-MS analysis of Adansonia digitata seeds oil}

The GC-MS analysis of the studied oil revealed the presence of 24 constituents (Table No.2). The typical total ion of the following constituents was detected in the chromatogram (Figure No.1).

\section{As major constituents}

The mass spectrum of 9-octadecanoic acid methyl ester is displayed in (Figure No.2). The peak at $\mathrm{m} / \mathrm{z} 296$, which appeared at R.T. 18.358 corresponds 
$\mathrm{M}^{+}\left[\mathrm{C}_{19} \mathrm{H}_{36} \mathrm{O}_{2}\right]^{+}$. The signal at $\mathrm{m} / \mathrm{z} 264$ accounts for loss of a methoxyl function.

The mass spectrum of 9,12-octadecanoic acid methyl ester is shown in (Figure No.3). The peak at $\mathrm{m} / \mathrm{z}$ 294, which appeared at R.T. 18.292 in total ion chromatogram, corresponds $\mathrm{M}^{+}\left[\mathrm{C}_{19} \mathrm{H}_{34} \mathrm{O}_{2}\right]^{+}$. The signal at $\mathrm{m} / \mathrm{z} 263$ corresponds to loss of a methoxyl function.

The mass spectrum of hexadecanoic acid methyl ester is depicted in (Figure No.4). The signal at $\mathrm{m} / \mathrm{z} 270$ (R.T. 15.688) corresponds $\mathrm{M}^{+}\left[\mathrm{C}_{17} \mathrm{H}_{34} \mathrm{O}_{2}\right]^{+}$. The signal at $\mathrm{m} / \mathrm{z} 239$ is due to loss of a methoxyl.

The mass spectrum of methyl stearate as shown in (Figure No.5).The signal at $\mathrm{m} / \mathrm{z}$ 298(R.T. 18.527) corresponds $\mathrm{M}^{+}\left[\mathrm{C}_{19} \mathrm{H}_{38} \mathrm{O}_{2}\right]^{+}$, while the peak at $\mathrm{m} / \mathrm{z} 267$ corresponds to loss of a methoxyl.

The mass spectrum of Methyl 2octylcyclopropene is depicted in (Figure No.6).The signal at $\mathrm{m} / \mathrm{z} 294$ (R.T. 18.015) corresponds
$\mathrm{M}^{+}\left[\mathrm{C}_{17} \mathrm{H}_{34} \mathrm{O}_{2}\right]^{+}$. The signal at $\mathrm{m} / \mathrm{z} 239$ is due to loss of a methoxyl.

\section{Antimicrobial activity}

The oil was screened for antimicrobial activity against five standard microorganisms. The average of the diameters of the growth inhibition zones are shown in (Table No.3). The results were interpreted in terms of the commonly used terms ( $>9 \mathrm{~mm}$ : inative; 9 $12 \mathrm{~mm}$ :partially active; $13-18 \mathrm{~mm}$ :active $<18 \mathrm{~mm}$ : very active). (Table No.3). also represent the antimicrobial activity of standard antibacterial and antifungal chemotherapeutic agents against standard bacteria and fungi respectively.

\section{Antioxidant activity}

The percentage of DPPH radical scavenging activity (RSA) of essential oil was $19 \%$ lower than Standard (Table No.4). The results indicated that of Adansonia digitata seeds contain anti-oxidant compounds this is in agreement with previously reported studies [11].

Table-1: Test organisms

\begin{tabular}{|c|l|c|}
\hline S.No & Microorganisms & Type \\
\hline 1 & Bacillus subtitlis & G+ve \\
\hline 2 & Staphylococcus aurous & G+ve \\
\hline 3 & Escherichia coli & G-ve \\
\hline 4 & Pseudomonas aeruginosa & G-ve \\
\hline 5 & Candida albcans & Fungus \\
\hline
\end{tabular}

Table-2: Constituents of Adansonia digitata seeds oil

\begin{tabular}{|c|c|c|c|c|}
\hline S.No & Name & R.Time & Area & Area\% \\
\hline 1. & Methyl tetradecanoate & 14.276 & 1791813 & 0.50 \\
\hline 2. & cis-5-Dodecenoic acid, methyl ester & 15.137 & 82173 & 0.02 \\
\hline 3. & 5-Octadecenoic acid, methyl ester & 15.248 & 70642 & 0.02 \\
\hline 4. & Pentadecanoic acid, methyl ester & 15.413 & 349131 & 0.10 \\
\hline 5. & 7,10-Hexadecadienoic acid, methyl ester & 16.192 & 109135 & 0.03 \\
\hline 6. & 7-Hexadecenoic acid, methyl ester, (Z)- & 16.256 & 302005 & 0.08 \\
\hline 7. & 9-Hexadecenoic acid, methyl ester, (Z)- & 16.297 & 1089533 & 0.30 \\
\hline 8. & Hexadecanoic acid, methyl ester & 16.534 & 82424943 & 22.78 \\
\hline 9. & Methyl 9,12-heptadecadienoate & 17.247 & 1692192 & 0.47 \\
\hline 10. & cis-10-Heptadecenoic acid, methyl ester & 17.300 & 2182275 & 0.60 \\
\hline 11. & Heptadecanoic acid, methyl ester & 17.529 & 1642547 & 0.45 \\
\hline 12. & Methyl 2-octylcyclopropene-1-heptanoate & 18.015 & 21986105 & 6.08 \\
\hline 13. & 9,12-Octadecadienoic acid (Z,Z)-, methyl ester & 18.292 & 83529035 & 23.08 \\
\hline 14. & 9-Octadecenoic acid (Z)-, methyl ester & 18.358 & 90728104 & 25.08 \\
\hline 15. & Methyl stearate & 18.527 & 24833196 & 6.86 \\
\hline 16. & cis-11,14-Eicosadienoic acid, methyl ester & 18.973 & 11806173 & 3.26 \\
\hline 17. & cis-10-Nonadecenoic acid, methyl ester & 19.347 & 18843516 & 5.21 \\
\hline 18. & cis-11-Eicosenoic acid, methyl ester & 20.165 & 3080587 & 0.85 \\
\hline 19. & Eicosanoic acid, methyl ester & 20.366 & 6735316 & 1.86 \\
\hline 20. & Docosanoic acid, methyl ester & 22.072 & 2216227 & 0.61 \\
\hline 21. & Tricosanoic acid, methyl ester & 22.875 & 571977 & 0.16 \\
\hline 22. & Tetracosanoic acid, methyl ester & 23.651 & 1823150 & 0.50 \\
\hline 23. & Gamma-Sitosterol & 24.288 & 3810842 & 1.05 \\
\hline 24. & Gamma-Tocopherol & 26.714 & 175818 & 0.05 \\
\hline
\end{tabular}


Table-3: Antioxidant activity of Adansonia digitata seeds oil

\begin{tabular}{|l|l|l|l|l|l|l|}
\hline Drug & Conc. $(\mathbf{m g} / \mathbf{m l})$ & E.c & P.s & S,a & B.s & C.a \\
\hline Seeds Oil & 100 & 11 & 15 & 17 & 16 & 18 \\
\hline Gentamicin & 40 & 22 & 21 & 19 & 25 & - \\
\hline Clotrimazole & 40 & - & - & - & - & 28 \\
\hline
\end{tabular}

Note: E.c = Escherichia coli, P.s = Pseudomonas aeruginosa, $\mathrm{S} . \mathrm{a}=$ Staphylococcus aureus, B.s $=$ Bacillus subtitles, C.a $=$ Candida albcans.

Table-4: Antioxidant activity of Adansonia digitata seeds oil

\begin{tabular}{|c|l|l|}
\hline S. No & Sample Code & \%RSA \pm SD $($ DPPH) \\
\hline 1 & Seeds oil & $19.00 \pm 0.08$ \\
\hline Standard & Propyl gallate & $95.00 \pm 0.02$ \\
\hline
\end{tabular}

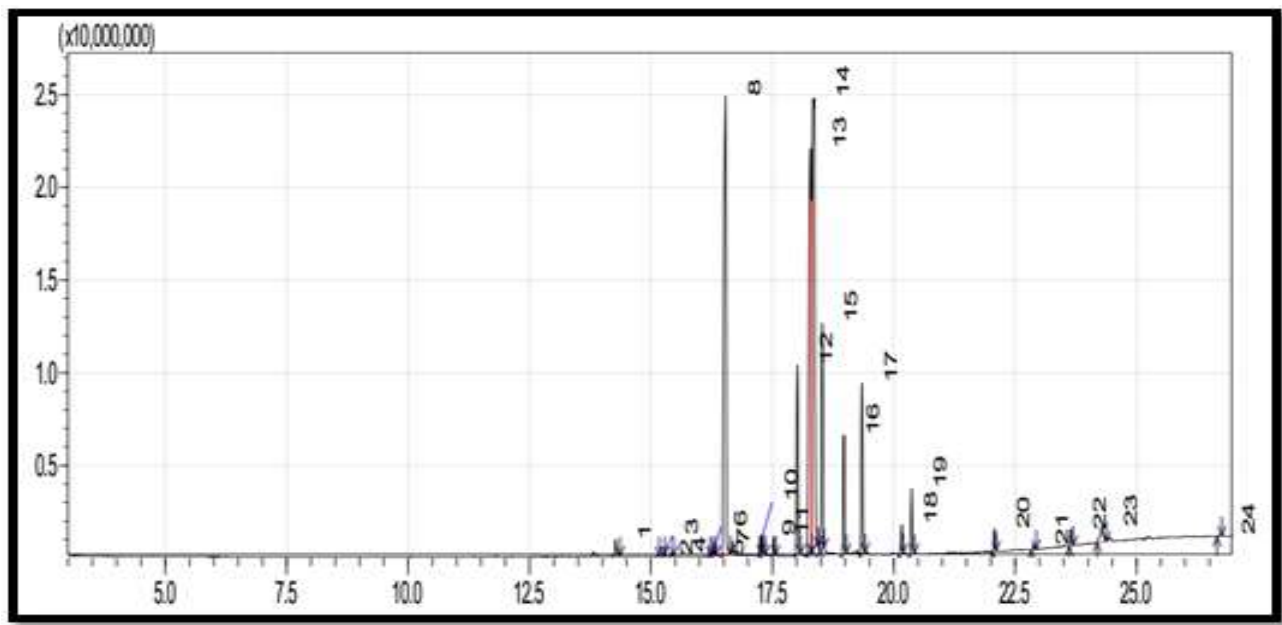

Fig-1: Chromatograms of Adansonia digitata seeds oil

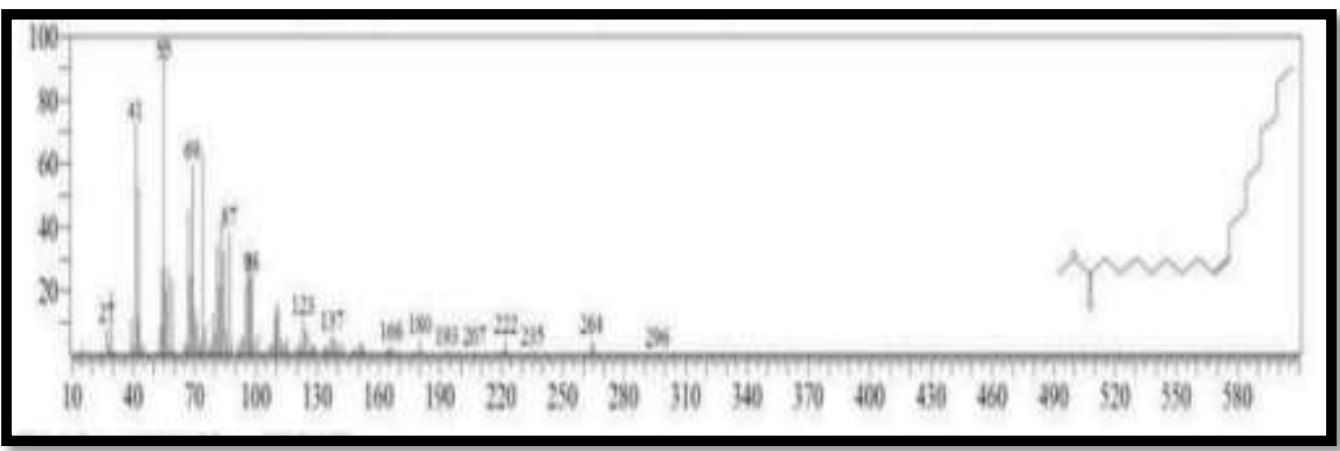

Fig-2: Mass spectrum of 9-octadecanoic acid methyl ester

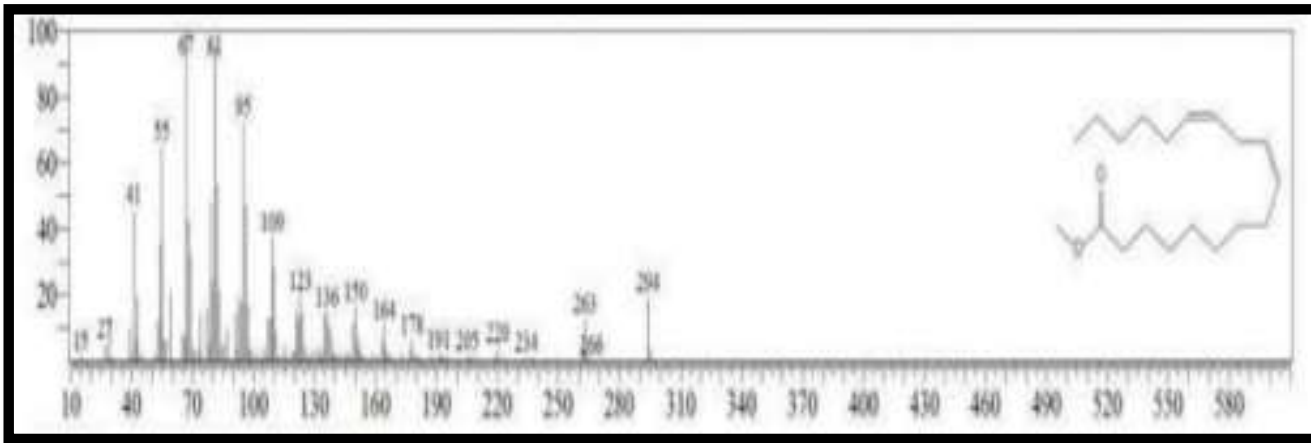

Fig-3: Mass spectrum 9, 12-Octadecadienoic acid $(\mathrm{Z}, \mathrm{Z})$-, methyl ester 


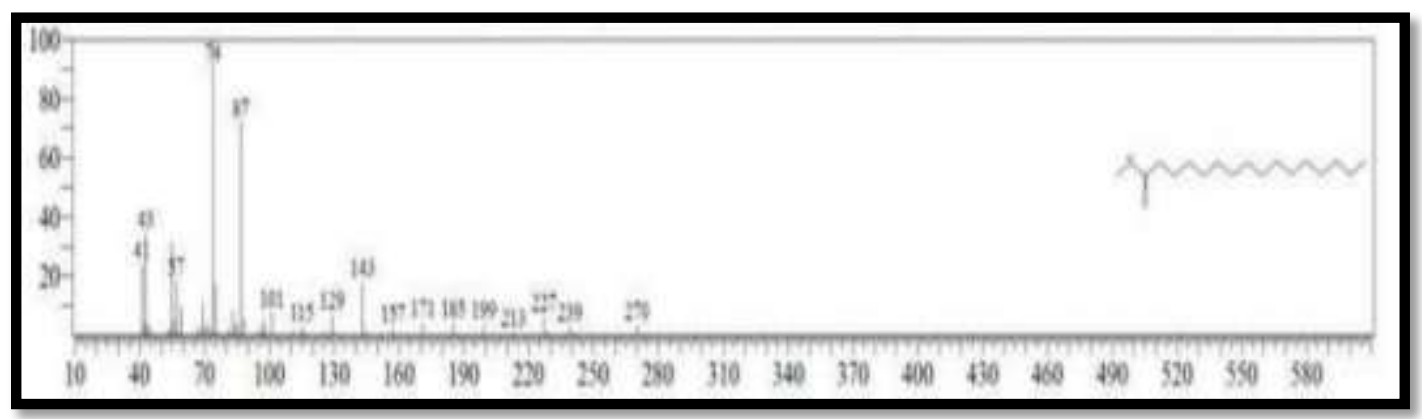

Fig-4: Mass spectrum Hexadecanoic acid, methyl ester

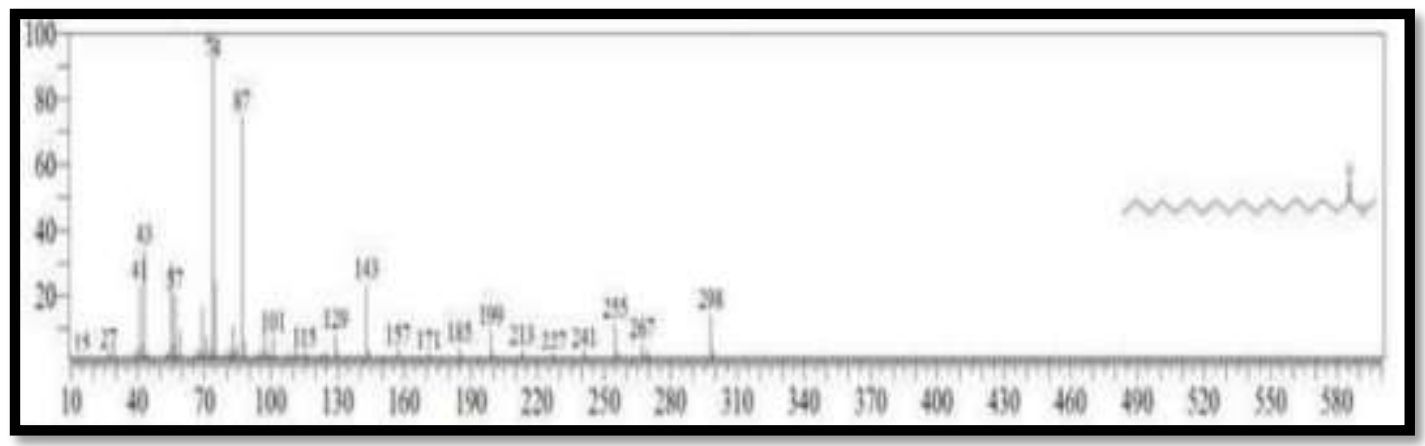

Fig-5: Mass spectrum of methyl stearate

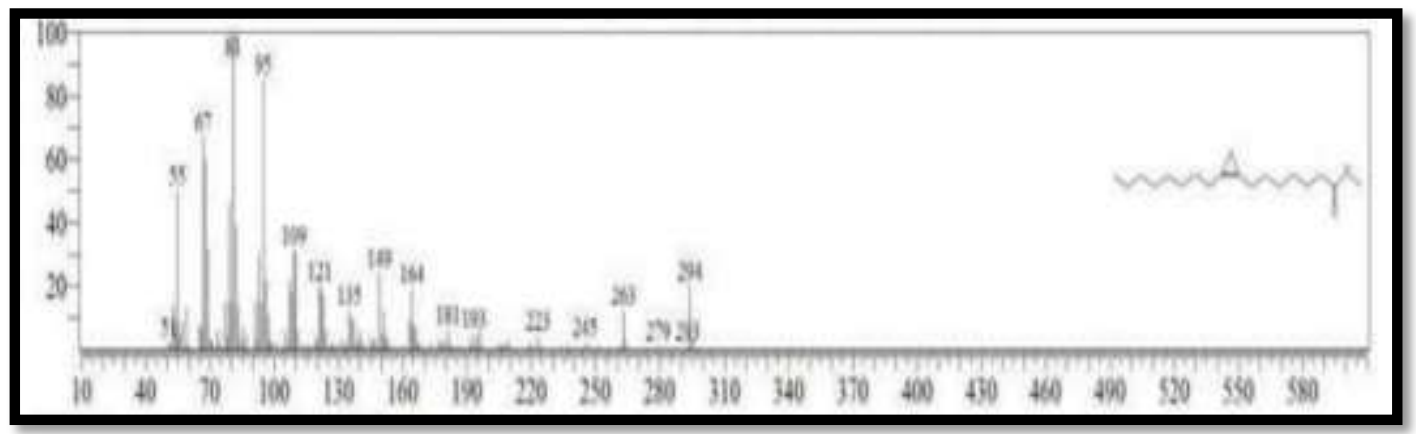

Fig-6: Mass spectrum Methyl 2-octylcyclopropene-1-heptanoate

\section{Conclusion}

The results indicated that the hexane extract of the Baobab seeds oil content twenty four compounds and has potential antimicrobial and anti-oxidant activity. The oil showed activity against Bacillus subtilis, Pseudomonas aeroginosa, Staphylococcus aureus, and the yeast Candida albicans. But it was partially active against against Escherichia coli.

\section{ACKNOWLEDGMENT}

We thank the members of Medicinal and Aromatic Plants Research Institute and University of medical Sciences and technology Khartoum Sudan for biological activity measurements and GC/MS facilities.

\section{Conflict of Interest}

There is no conflict of interest.

\section{REFFERENCE}

1. Hoareau, L., \& DaSilva, E. J. (1999). Medicinal plants: a re-emerging health aid. Electronic Journal of biotechnology, 2(2), 3-4.

2. Kamatou, G. P. P., Vermaak, I., \& Viljoen, A. M. (2011). An updated review of Adansonia digitata: A commercially important African tree. South African Journal of Botany, 77(4), 908-919.

3. De Caluwé, E., Halamová, K., \& Van Damme, P. (2009). Baobab (Adansonia digitata L.): a review of traditional uses, phytochemistry and pharmacology.

4. Nguta, J. M., Mbaria, J. M., Gakuya, D. W., Gathumbi, P. K., \& Kiama, S. G. (2010). Antimalarial herbal remedies of Msambweni, Kenya. Journal of Ethnopharmacology, 128(2), 424-432.

5. Khan, M., Shingare, M. S., Zafar, R., Ramesh, D., \& Siddiqui, A. R. (2006). Analgesic activity of 
fixed oil of Adansonia digitata. Indian Journal of Natural Products, 22, 20-21.

6. Masola, S. N., Mosha, R. D., \& Wambura, P. N. (2009). Assessment of antimicrobial activity of crude extracts of stem and root barks from Adansonia digitata (Bombacaceae)(African baobab). African Journal of Biotechnology, 8(19).

7. Selvarani, V. (2009). Multiple inflammatory and antiviral activities in Adansonia digitata (Baobab) leaves, fruits and seeds. Journal of Medicinal Plants Research, 3(8), 576-582.

8. Denloye, A. A. B., Teslim, K. O., \& Fasasi, O. A. (2006). Insecticidal and repellency effects of smoke from plant pellets with or without Dallethrin 90 EC against three medical insects. Journal of Entomology, 3(1), 9-15.

9. Shukla, Y. N., Dubey, S., Jain, S. P., \& Kumar, S. (2001). Chemistry, biology and uses of Adansonia digitata-a review. Journal of Medicinal and Aromatic Plant Sciences, 23(3), 429-434.

10. Suliman, M. B., Mohammed, A. A., \& Nour, A. H. (2017). Chemical composition and antibacterial activity of Sudanese Balanites Aegyptiaca del kernel oil. Chemistry of Advanced Materials, 2(2), 14-21.

11. Lopez-Bote, C. J., Gray, J. I., Gomaa, E. A., \& Flegal, C. J. (1998). Effect of dietary administration of oil extracts from rosemary and sage on lipid oxidation in broiler meat. British poultry science, 39(2), 235-240.

12. Shimada, K., Fujikawa, K., Yahara, K., \& Nakamura, T. (1992). Antioxidative properties of xanthan on the autoxidation of soybean oil in cyclodextrin emulsion. Journal of agricultural and food chemistry, 40(6), 945-948. 